\title{
Construction and Properties of Hybrids Obtained in Interspecific Crosses between Streptomyces coelicolor A3(2) and Streptomyces griseus $\mathrm{Kr} .15$
}

\author{
By NATALIE D. LOMOVSKAYA, TATJANA A. VOEYKOVA AND \\ NORA M. MKRTUMIAN \\ Institute of Genetics and Selection of Industrial Micro-organisms, \\ I 3545 Moscow, $a \mid b$ 825, U.S.S.R.
}

(Received I6 June 1976)

\begin{abstract}
SUMMAR Y
Recombinants between Streptomyces coelicolor A3(2) and Streptomyces griseus Kr.I5 were obtained using methods of hybrid construction. Recombinant RcgI, obtained from a cross between $S$. griseus and a $S$. coelicolor UF (SCPI ${ }^{-}$) strain, phenotypically resembled $S$. coelicolor UF strains and in crosses with a $S$. coelicolor $\mathrm{NF}$ donor strain produced recombinant progeny at a frequency of $100 \%$. Recombinant Rcg3, like SCPI-carrying $S$. coelicolor strains, inhibited SCPI ${ }^{-}$strains of $S$. coelicolor and in crosses with a UF recipient strain of $S$. coelicolor generated recombinants at high frequency. In crosses between $S$. griseus and RcgI the frequency of recombinant formation was increased about Ioo-fold relative to crosses between $S$. griseus and $S$. coelicolor. Effective transfer of $S$. griseus and Rcg3 chromosomal markers into RcgI and $S$. coelicolor, respectively, indicated that $S$. griseus had donor properties.

Studies of the ability of recombinants to support phage growth indicated that parental chromosomal fragments containing genes involved in control of phagereceptor formation and intracellular growth were present in the hybrids. Grisinproducing recombinants, capable of restricting phages attacking $S$. coelicolor and $S$. griseus, were obtained.
\end{abstract}

\section{INTRODUCTION}

Cross-breeding procedures are used extensively in animal and plant breeding but have not been applied on a large scale for the selection of micro-organisms producing biologically active substances. The exploitation of techniques for obtaining hybrids of antibioticproducing actinomycetes, especially hybrids between strains submitted to divergent selection and those between different actinomycete species, should facilitate the development of improved strains and enhance the possibility of their genetic analysis.

Studies of the capacity of various strains, species and genera of Enterobacteriaceae to form hybrids have shown that integration of a donor fragment depends on the extent of genetic and physical homology between the parental genomes (Demerec, I965; Sanderson, I97I ; Brenner \& Falkow, I97I). Extensive studies of bacterial hybrids show that they may be helpful not only in solving taxonomic problems and in studying the behaviour of foreign genes in a different host, but also in elucidating peculiarities of host-phage relationships. For example, it has been possible to study the influence of the Shigella genome on the functioning of $\lambda$ genes by constructing Escherichia coli-Shigella hybrids that have inherited $E$. coli genes controlling receptor synthesis for $\lambda$ adsorption (Gemski, Alexeichik \& Baron, 1972). It has also been shown that substitution of $E$. coli chromosomal genes by Klebsiella 
nitrogen-fixation genes produces hybrids which, unlike the $E$. coli parental strain, cannot adsorb phage $\phi \mathrm{XI} 74$ (Cannon et al., 1974). Baron et al. (1970) and Friedman \& Baron (1974) demonstrated that E. coli-Salmonella typhosa hybrids had acquired the ability of $E$. coli to adsorb phage $\lambda$, but the phage did not grow in these hybrids because they did not contain the bacterial locus involved in phage gene $\mathrm{N}$ expression. Using hybrids of $E$. coli Hfr and Salmonella typhimurium carrying various host specificity genes of $E$. coli, Colson \& Colson (1972) identified a formerly undetected system of restriction and modification in Salmonella.

Effective exchange of chromosomal markers between derivatives of Streptomyces coelicolor $\mathrm{A} 3(2)$ is known to take place via a process similar to conjugation in other bacteria and is promoted by the plasmid SCPI (Vivian \& Hopwood, 1970; Vivian, I97I; Hopwood et al., I973).

The similarity of the genetic maps of some representatives of the genus Streptomyces (Hopwood, 1967; Friend \& Hopwood, I97I; Coats \& Roeser, I97I ; Alačević, StrašekVešligaj \& Sermonti, I973; Baumann \& Kocher, 1976; Matselyukh, 1976) and the data on 'infectious' transfer of the plasmid SCPr between various Streptomyces species (Hopwood \& Wright, 1973) suggested that a study of hybrid formation within Streptomyces strains and species was feasible.

In a previous paper we reported crosses between $S$. coelicolor A3(2) and Streptomyces lividans 66, and described characteristics of the recombinants obtained (Alikhanian, Lomovskaya \& Danilenko, 1976). In this paper we describe the methods used to construct hybrids between $S$. coelicolor A3(2) and Streptomyces griseus Kr.I5, and the properties of these hybrids. Special attention is paid to the reaction of the hybrids to actinophages which are known to be capable of interfering with the industrial production of the antibiotic grisin. Grisin production is usually less in strains that are resistant to actinophages. Moreover, it is not easy to obtain, by selection, mutants which block the intracellular growth of virulent phages, or have lost the ability to adsorb a temperate phage. It is, therefore, advantageous to obtain hybrids which have received resistance genes from parental strains that are intrinsically phage resistant.

\section{METHODS}

Strains and phages. The actinomycete strains used are listed in Table I. Genetic symbols are as given by Hopwood et al. (1973). Polyauxotrophic derivatives of $S$. coelicolor A3(2), strains $853, \mathrm{~A} 585, \mathrm{~A} 6 \mathrm{I} 7$, and actinophage VP5 of $S$. coelicolor were kindly supplied by D. A. Hopwood. Strains si 8, s32, SI 79 and $\operatorname{si} 87$ were constructed as recombinants in crosses between derivatives of strain A3(2). Streptomyces griseus produces the antibiotic grisin (grisemin) (Korzybski, Kowszyk-Gindifer \& Kuryłowicz, 1969; Krasilnikov, 1970). A derivative, K806, which produced more antibiotic than wild-type strains of $S$. griseus Kr.I5, was selected after a single treatment of $S$. griseus Kr.I5 with $N$-methyl- $N^{\prime}$-nitro- $N$ nitrosoguanidine (NTG) as described by Delić, Hopwood \& Friend (1970). The strain S. griseus KI 55 was obtained after a single treatment with ethylenimine (Alikhanian, I969). Strain KI55 required histidine and was resistant to phage Pg8r. Phages Pg8I, PgIoo and $\mathrm{Pg}_{56}$, acting on $S$. griseus Kr.I5, and phages $\mathrm{VP}_{5}$ and $\phi 448$, acting on $S$. coelicolor, were used in host-range studies.

Media and techniques. Complete (CM) and minimal (MM) media and crossing procedures were essentially as described previously (Lomovskaya, Emeljanova \& Alikhanian, I971). Crosses between str-s and str-r strains were performed in two ways. (I) Spore suspensions of the parent strains were incubated separately for $6 \mathrm{~h}$ in peptone broth (Lomovskaya et al., 
Table I. Characteristics of actinomycetes used

Strain

S. coelicolor A3(2) wild type

$$
\text { A585 }
$$

A617

853

SI 86

SI 8

s32

SI 79

S. lividans 66

S. griseus Kr.15 K806

KI55

Recombinants

S. coelicolor A3(2) RcgI $(\mathrm{A} 6 \mathrm{I} 7 \times \mathrm{K} 806) \dagger$

$\times$ S. griseus Kr.I 5 Rcg2 $(\mathrm{RcgI} \times \mathrm{KI} 55)$

$\mathrm{Rcg}_{3}(\mathrm{~A} 6 \mathrm{I} 7 \times \mathrm{K} 806)$

Rcg5 (RcgI $\times$ KI 55)

Rcg7 (RcgI $\times$ KI 55)

RcgiI (SI $8 \times$ K806)
Genetic markers*

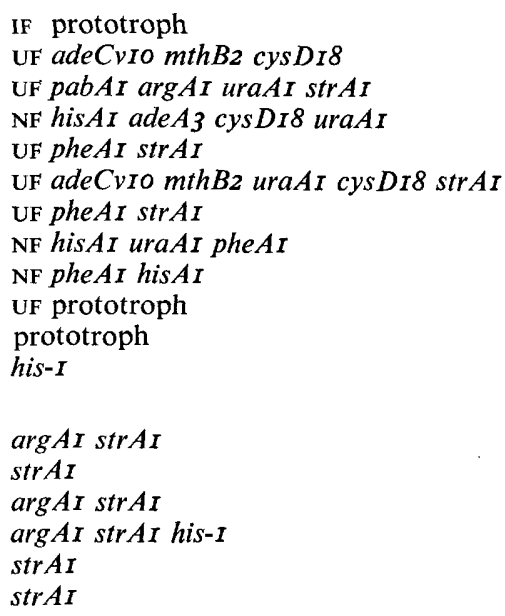

* NF-like strains harbour the plasmid SCPI integrated into the chromosome. UF strains lack the plasmid. IF strains contain the plasmid in the autonomous state (Vivian, 1971).

$\uparrow$ Parental strains of an each recombinant are given in parentheses.

1972) on the surface of CM plates, and then germinated spores of each of the parents were sedimented and spread together on CM slants containing streptomycin $\left(50 \mu \mathrm{g} \mathrm{ml} \mathbf{m}^{-1}\right)$. (2) Spore suspensions of the parent strains were mixed and grown on CM plates, which contained no streptomycin, for about Io h: during this time, the parental strains did not produce sufficient antibiotic to arrest each other's growth. The mixed culture was then sedimented and transferred to CM slants containing streptomycin, to eliminate the str-s parental strain.

The progeny from single colonies formed on $\mathrm{MM}$, which failed to give growth on the same medium and were probably heteroclones or heterokaryons, were analysed as follows. Suspended spores filtered through cotton wool were seeded on CM and the resulting single colonies were transferred to master plates and replica-plated to diagnostic media to analyse the colony genotypes.

The inhibiting properties of cultures producing antibiotics and the ability of SCPIcarrying strains to inhibit strains lacking the plasmid were tested by overlaying 24 -h-old cultures on plates with spore suspensions of test cultures in soft agar.

The fertility of the progeny from crosses $\mathrm{Rcg}_{3} \times \mathrm{A}_{5} 85$ and $\mathrm{SI}_{79} \times \mathrm{Rcg}$ I was tested as described by Hopwood et al. (1969) and Vivian \& Hopwood (1970). Streptomyces coelicolor A6I 7, A585 and s32 were used as tester strains. Crosses of UF strains with the A3(2) IF strain served as controls. The UF tester strain chosen depended on the markers to be tested. Those of tested strains were situated in the fragment most often included in recombinants from the donor chromosome.

Phage techniques and antibiotic production tests were as described by Lomovskaya et al. (197I) and Zvenigorodsky et al. (I975). Adsorption of actinophages on to 6-h-old germinated spores was studied by adding phage to an equal volume of spore suspension at a low multiplicity of infection. The efficiency of adsorption was determined by measuring the decrease in free phages after centrifuging the mixture. 
Table 2. Generation of recombinants from crosses of $S$. coelicolor A3(2) strains in the presence and absence of streptomycin

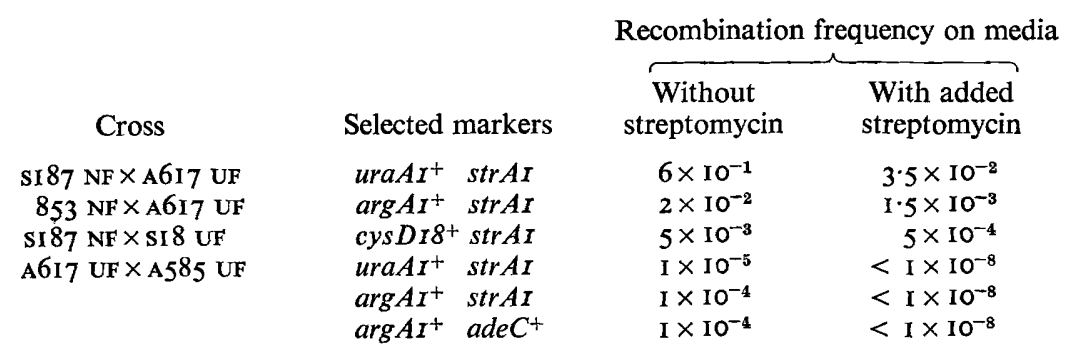

\section{RESULTS}

Recombination between $S$. coelicolor $\mathrm{A} 3(2)$ and S. griseus Kr.I5 strains

Mating in actinomycete crosses is known to occur in mixed cultures of S. coelicolor A3(2) and $S$. griseus Kr.I5 on CM. Since these two strains are mutually antagonistic, arresting each other's growth in mixed culture, it was impossible to grow them together and to ascribe $S$. griseus to any known fertility type. Thus, it was necessary to create conditions which would allow normal crossing between the strains. It would be possible, if crosses were made in the presence of streptomycin, to eliminate one of the parent strains during the early stages of mating (Hopwood, 1973). In a model cross between str-s NF (donor) and str-r UF (recipient) strains in which spores of the parents were germinated separately and then mixed on medium containing streptomycin, recombinants emerged at low frequency (Table 2). This indicated that, as in crosses between $\mathrm{Hfr} s t r-s$ and $\mathrm{F}^{-}($str-r $)$strains of $E$. coli (Hayes, 1952), an actinomycete $s t r-s$ donor can donate its chromosome or chromosomal fragment to a str-r recipient in the presence of streptomycin. Recombinants should arise under these conditions provided that a conjugational type of transfer and not heterokaryosis takes place. No recombinants were detected in crosses between str-s and $s t r-r$ UF strains in which spores germinated separately without streptomycin were mixed and crossed in the presence of streptomycin. Lack of recombinants in this case might indicate that recombinants from the UF $\times$ UF cross were formed due to genetic exchange in heterokaryons (Table 2).

Because the fertility type of $S$. griseus Kr.I5 was not known, crosses were conducted using two combinations: (i) using a str-r recipient UF strain of $S$. coelicolor and a str-s strain of $S$. griseus; and (ii) using a str-s NF donor strain of $S$. coelicolor and a str-r strain of $S$. griseus. In crosses of the first type $(\mathrm{K} 806 \times \mathrm{A} 6 \mathrm{I} 7)$ in the presence of streptomycin, conducted in the same way as in the model cross, we detected colonies growing on selective plates (selected markers $\mathrm{uraAI}^{+} \operatorname{str} A I$ ). Colonies that developed only substrate mycelium appeared at a frequency of approximately $10^{-4}$. After incubation for 10 to 12 days, some colonies formed patches with aerial mycelium and spores (Fig. I). Parental strains did not develop colonies of this type in the same conditions. On transfer to the same selective plates, the colonies failed to grow. Spores from each of 30 colonies were seeded on CM plates. In the progeny of 28 colonies only clones with the genotype of the parental strain $S$. coelicolor A617 were detected. Analysis of the progeny from the other two colonies showed that, from the first colony, I84 out of 200 clones analysed had the genotype of strain A6I 7 and I6 were $\arg A I$ strAI, and, from the second colony, I9I of 200 clones analysed had the genotype of strain A6I 7 and nine were $\arg A I \operatorname{str} A I$. 


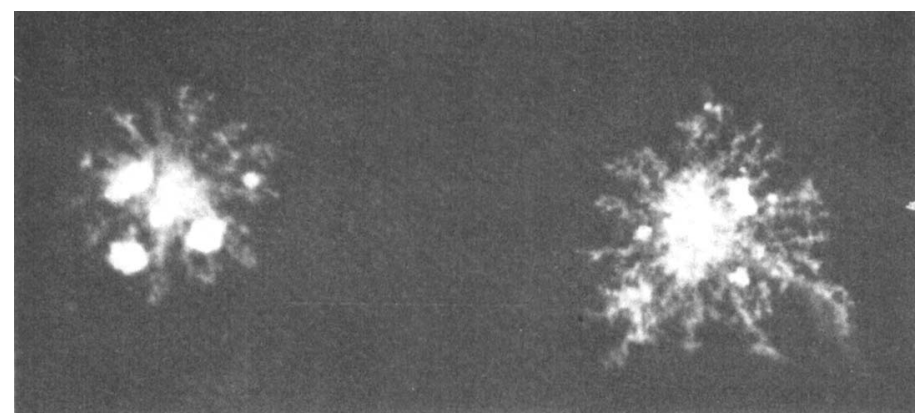

Fig. I. Colonies arising on selective medium from crosses between $S$. griseus K806 and S. coelicolor A6r 7 (selected markers $\mathrm{uraAI}^{+}$strAI). Patches of aerial mycelium and spores are shown.

\section{Characteristics of recombinants from crosses between $S$. griseus $\mathrm{K} 806$ and $S$. coelicolor $\mathrm{A} 6 \mathrm{I} 7$}

$\operatorname{ArgAI}$ strAI recombinants failed to produce the antibiotic that arrested the growth of both SCPI-carrying and $\mathrm{SCP}_{I^{-}}-S$. coelicolor strains. Recombinants from the progeny of the first colony, in contrast to those from the progeny of the second colony, had the inhibiting properties characteristic of $S$. coelicolor strains carrying the plasmid SCPI. A representative of similar recombinants from the progeny of the first colony was designated Rcg3, and one from the progeny of the second colony was designated Rcg I. Ura clones were not detected among $10^{4}$ progeny of both recombinants, suggesting that these recombinants showed no segregation in respect of $u_{r a}{ }^{+}$donated with the fragments of the $S$. griseus chromosome. $\mathrm{Rcg}_{3}$ inhibited an $\mathrm{SCP}_{1}-S$. coelicolor strain, but did not affect an SCPIcarrying strain and was resistant to the antibiotic produced by a strain carrying the SCPI plasmid. These results indicated that, though derived from a cross of $S$. griseus with a $S$. coelicolor UF $\left(\mathrm{SCPI}^{-}\right)$strain, $\mathrm{Rcg}_{3}$ phenotypically resembled strains bearing the SCPI plasmid. In contrast, $\mathrm{Rcg} I$ failed to arrest the growth of $\mathrm{SCPI}^{-}$strains and was sensitive to the antibiotic produced by an SCPI-carrying strain. Both recombinants were inhibited by $S$. griseus (Table 3, Fig. 2).

We examined the behaviour of $\mathrm{Rcg}_{3}$ in crosses with a $S$. coelicolor UF strain. In a cross with strain $\mathrm{A} 585$, recombinants arose at high frequency, as in crosses between $S$. coelicolor NF and UF strains. This enabled us to analyse crosses by plating on non-selective media. Table 4 shows the genotypes of the progeny from the Rcg $3 \times$ A585 cross. Unlike the situation in an NF $\times$ UF cross of $S$. coelicolor (Hopwood et al., 1969), many clones had the parental genotypes (83/240 with the Rcg3 genotype and 4/240 with strain A585 genotype) and there was a distinct ratio of recombinant classes. Figure $3 a$ shows the allele ratios of the I53 clones with recombinant genotypes: these ratios depart markedly from those expected from crosses between $S$. coelicolor NF and UF strains. Of I 53 recombinants analysed, I 45 had the phenotypic characteristic of SCPI-carrying strains in arresting the development of $S$. coelicolor $\mathrm{SCPI}^{-}$strains. In a qualitative test for the ability to generate recombinants with one of the UF tester strains $\mathrm{A5} 85, \mathrm{~A} 6 \mathrm{I} 7$ or $\mathrm{s} 32$, representatives of recombinants from this cross behaved like the donor strain of $S$. coelicolor, i.e. they produced recombinants with a high frequency, unlike the situation in the cross with an IF strain of $S$. coelicolor A3(2). As in all well known conjugational systems, effective transfer of the chromosome from $\mathrm{Rcg} 3$ into the UF strain of $S$. coelicolor may be due to the presence of fertility factor in this strain. For operational convenience we tentatively named this SGPI in Fig. $3 a$. 


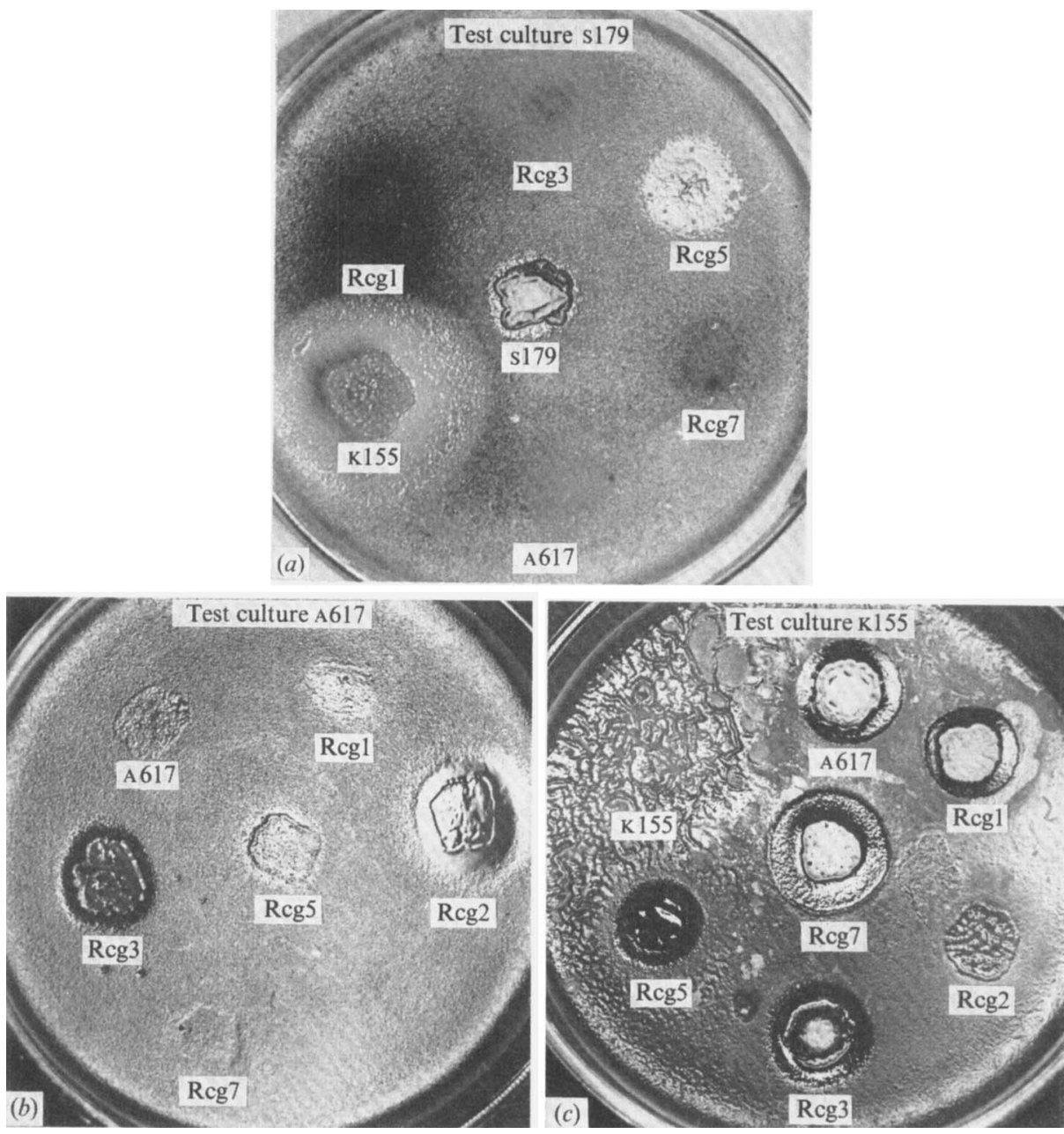

Fig. 2. Inhibition of (a) S. coelicolor SI 79 NF, (b) S. coelicolor A6I7 UF and (c) S. griseus KI 55 by recombinants from crosses between $S$. coelicolor and $S$. griseus. (a) Only strain KI55 inhibits the NF strain (light zone). (b) Only recombinants $\mathrm{Rcg} 2$ and $\mathrm{Rcg} 3$ inhibit the UF strain. Rcg3 forms dark zones of inhibition because patches produce dark pigment during growth. Rcg2 forms light zones (dark pigment is not produced). (c) The test culture KI 55 is inhibited by strains A6I 7, RcgI, Rcg3, Rcg5 and Rcg7.

Table 3. Cross-testing of antibiotic-producing strains of S. coelicolor A3(2) and $S$. griseus $\mathrm{Kr} . \mathrm{I} 5$ and their recombinants

\begin{tabular}{|c|c|c|c|c|c|c|c|c|c|}
\hline \multirow[b]{2}{*}{ Strains } & \multicolumn{9}{|c|}{ Indicator cultures } \\
\hline & $\begin{array}{c}\text { A6I7 } \\
\text { UF }\end{array}$ & $\begin{array}{c}\text { SI } 79 \\
\text { NF }\end{array}$ & K806 & KI 55 & $\operatorname{Rcg} I$ & $\mathrm{Rcg} 3$ & $\mathrm{Rcg} 7$ & Rcg2 & RcgII \\
\hline $\left.\begin{array}{l}\text { A617, RcgI } \\
\operatorname{Rcg} 5, \operatorname{Rcg} 7\end{array}\right\}$ & - & - & + & + & - & 一 & 一 & + & + \\
\hline SI 79, Rcg3 & + & - & + & + & + & - & + & + & + \\
\hline $\left.\begin{array}{l}\text { K806, K155, } \\
\operatorname{Rcg} 2, \operatorname{Rcg} I_{1}\end{array}\right\}$ & + & + & hibiti & $\begin{array}{c}- \\
-, \mathrm{n}\end{array}$ & $\begin{array}{c}+ \\
\text { ahibiti }\end{array}$ & + & + & - & - \\
\hline
\end{tabular}




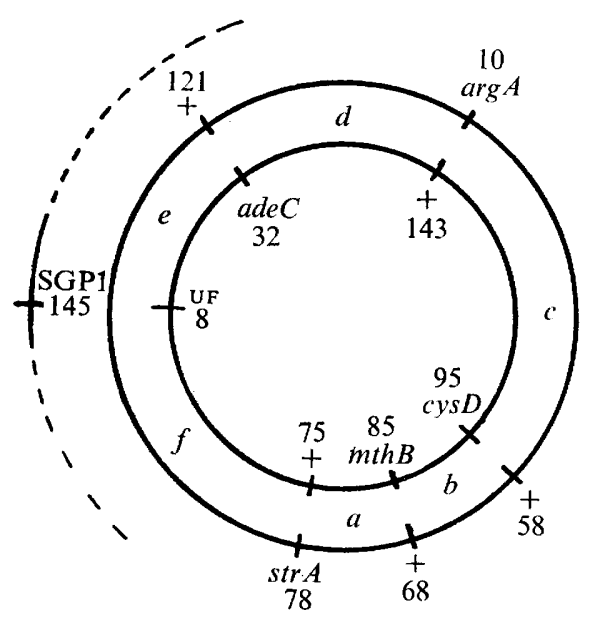

(a)

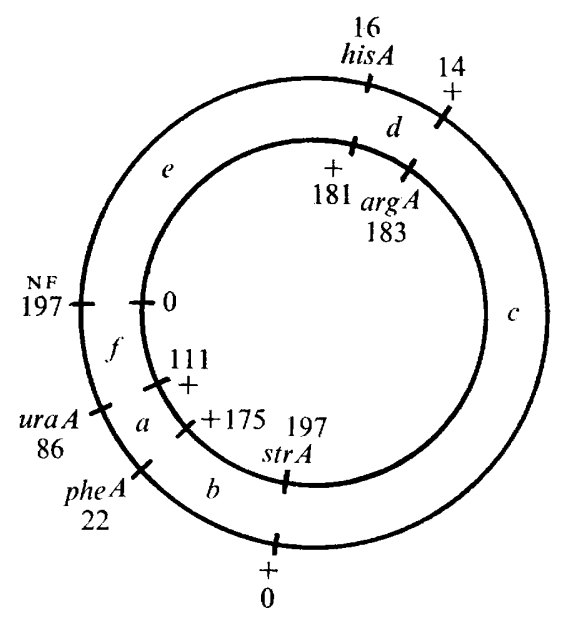

(h)

Fig. 3. Non-selective analysis of genotypes of haploid recombinants from the crosses $(a) \operatorname{Rcg} 3 \times \mathrm{A}_{5} 85$, parental genotypes omitted, and $(b)$ si $79 \times \mathbf{R c g I}$.

Table 4. Non-selective analysis of genotypes from crosses $\mathrm{Rcg}_{3} \times \mathrm{A}_{5} 85$ and $\mathrm{SI}_{79} \times \mathrm{Rcg}_{\mathrm{I}}$ *

\begin{tabular}{|c|c|c|c|}
\hline Genotype & $\begin{array}{l}\text { Crossover } \\
\text { in interval }\end{array}$ & $\begin{array}{l}\text { No. of } \\
\text { variants }\end{array}$ & Fertility type \\
\hline \multicolumn{4}{|c|}{ Cross Rcg 3 arg str $\times \mathrm{A}_{5} 85$ ade mth cys } \\
\hline ade mth cys & - & 4 & UF \\
\hline mth cys & $d, e$ & 8 & Recipient-like \\
\hline arg str & - & 83 & Donor-like \\
\hline mth cys & $d, f$ & 29 & Donor-like \\
\hline str & $c, d$ & 48 & Donor-like \\
\hline mth cys str & $a, d$ & 14 & Donor-like \\
\hline mth cys ade & $e, f$ & 24 & Donor-like \\
\hline cys str & $b, d$ & 5 & Donor-like \\
\hline arg cys str & $b, c$ & 4 & Donor-like \\
\hline ade mth cys str & $a, e$ & 3 & Donor-like \\
\hline arg mth cys & $c, f$ & 2 & Donor-like \\
\hline arg & $a, f$ & I & Donor-like \\
\hline arg mth & $b, f$ & I & Donor-like \\
\hline ade cys str & $b, e$ & I & Donor-like \\
\hline Prototroph & $a, c, d, f$ & 5 & Donor-like \\
\hline ade arg mth cys & $c, d, e, f$ & 2 & Donor-like \\
\hline ade cys & $a, b, e, f$ & I & Donor-like \\
\hline mth str & $a, b, c, d$ & I & Donor-like \\
\hline ade arg mth cys str & $a, c, d, e$ & I & Donor-like \\
\hline$m t h$ & $b, c, d, f$ & I & Donor-like \\
\hline cys & $a, b, d, f$ & I & Donor-like \\
\hline ade mth str & $a, b, c, e$ & I & Donor-like \\
\hline
\end{tabular}

Cross $\mathbf{S 1} 79$ his ura phe $\times \mathrm{RcgI}$ arg str

$\begin{array}{llrl}\text { arg str } & e, f & \text { I IO } & \text { NF } \\ \text { ura arg str } & a, e & 58 & \text { NF } \\ \text { ura phe his str } & b, c & \text { I I } & \text { NF } \\ \text { ura phe arg str } & b, e & \text { I I } & \text { NF } \\ \text { ura arg his str } & a, d & 4 & \text { NF } \\ \text { arg his str } & d, f & \text { I } & \text { NF } \\ \text { str } & c, d, e, f & \text { I } & \text { NF } \\ \text { ura str } & a, c, d, e & \text { I } & \text { NF }\end{array}$

* See Fig. $3(a, b)$. 
The behaviour of Rcg I in crosses with $S$. coelicolor NF strains was similar to that of a UF strain. The results of non-selective genetic analysis of recombinants from the cross between $S$. coelicolor NF and Rcg I suggest that RcgI acts as a recipient. All the progeny, including variants with the genotype of a UF strain, possessed the phenotypic characteristic of SCPI plasmid-carrying strains (Table 4 , Fig. $3 b$ ) and in crosses with UF tester strains behaved as donor strains.

\section{Recombinants carrying different parental contributions}

The results presented above demonstrate that recombinants between $S$. coelicolor and $S$. griseus were not easily detected in crosses conducted in the presence of streptomycin. The following technique was found to be more appropriate. Spores of both parents were mixed and inoculated on agar, and the resulting young mixed culture was transferred to medium containing streptomycin at various times before the antibiotic produced by the donor strain prevented further development of the recipient strain. Colonies were readily recognizible on selective medium when the mixed cultures were transferred after incubation for 6 to $\mathrm{I} 8 \mathrm{~h}$, but the number of such colonies was markedly reduced if the mixed culture was transferred after longer incubation times. The largest number of colonies was obtained when parental mixtures were transferred after Io $\mathrm{h}$. In the cross $\mathrm{K} 806 \times \mathrm{si} 8$ (selected markers ade $C^{+} \operatorname{str} A I$ ), colonies were formed at a frequency of $2 \times 10^{-3}$ to $5 \times 10^{-3}$ on selective plates, but when transferred to the same selective plates, they failed to grow. Twenty such colonies were seeded on CM. Only variants with the genotype of the parental strain SI 8 were detected among 100 progeny analysed from each of 17 colonies. Among the progeny from the other three colonies (Table 5), segregants ura mth cys str and str were detected as well as those with the genotype of the parental strain SI8. Str recombinants and strain K806 produced similar amounts of grisin. A representative of this recombinant class was designated RcgII.

To construct recombinants carrying different contributions from the parental $S$. griseus chromosome, RcgI was crossed with $S$. griseus $\mathrm{KI} 55 . \mathrm{ArgAI}^{+}$and $\operatorname{str} A \mathrm{I}$ served as selected markers. Genetic exchange between these strains may occur more readily because the parental chromosomes had $S$. griseus chromosomal fragments of complete homology. Colonies were detected on selective media at a frequency of approximately $5 \times 10^{-1}$ and failed to grow when transferred to the same media. Recombinants with new combinations of chromosomal markers were found among the progeny of three out of seven such colonies when about 100 clones from each colony were analysed (Table 6). The inhibiting properties of representatives of recombinant classes are shown in Table 3. Rcg5 and Rcg7 have the same properties as the parental strain RcgI. In contrast, $\mathrm{Rcg} 2$ produced the antibiotic that specifically inhibits $S$. coelicolor SCPI-carrying and $\mathrm{SCPI}^{-}$strains but not $S$. griseus KI55. While growing in a liquid medium, $R \operatorname{cg} 2$ produced grisin at a level similar to that of the parental strain KI55.

\section{Host-phage relationships}

Recombinants were used to determine the host range of the two groups of actinophages, each acting specifically on one of the parental strains and being unable to adsorb to the other (Tables 7 and 8). Phages $\phi 448$ and VP5 were able to adsorb to and grow in strains of S. coelicolor and S. lividans. Phages Pg8I, PgIoo and Pg56 behaved in S. griseus K806 host in the same manner. Strain Kr 55 was resistant to phage Pg8I: though able to adsorb to this strain, the phage failed to produce plaques. $\mathrm{Rcg}_{\mathrm{I}}, \mathrm{Rcg} 3$ and $\mathrm{Rcg} 5$ were similar to $S$. coelicolor in respect of all phages examined. $R c_{7}, R_{c g}$ and $R \operatorname{cgI} I$ differed from both parental strains in their ability to adsorb and support phage growth. Phage Pg8I on lawns of Rcg2 
Table 5. Genotypes of the progeny of colonies formed on $M M$ from the cross between strains $\mathrm{K} 806$ and $\mathrm{SI} 8$

$\begin{array}{cccr}\text { No. of progeny analysed with genotype } \\ \begin{array}{c}\text { Colony } \\ \text { no. }\end{array} & \begin{array}{c}\text { ade ura mth } \\ \text { cys str }\end{array} & \begin{array}{c}\text { ura mth } \\ \text { cys str }\end{array} & \text { str } \\ \text { I } & 82 & 9 & 0 \\ 9 & 98 & \text { I } 2 & 0 \\ \text { I I } & \text { IO4 } & 0 & \text { I } 4\end{array}$

Table 6. Genotypes of the progeny of colonies formed on MM from the cross between strains $\mathrm{Rcg} \mathrm{I}$ and $\mathrm{KI} 55$

No. of progeny analysed with genotype:

Colony no.

2
5
7
9
10
11
I 2

$$
\arg A I \operatorname{str} A I
$$

69

116

15

150

I 25

I32

I I I

$\begin{array}{rr}\text { strAI } & \arg A I \text { his } \\ \mathrm{I} 6 & 0 \\ 0 & 4 \\ \mathrm{I} 25 & 0 \\ 0 & 0 \\ 0 & 0 \\ 0 & 0 \\ 0 & 0\end{array}$

Table 7. Efficiency of actinophage adsorption to actinomycete strains Efficiency of adsorption (\%)

\begin{tabular}{|c|c|c|c|c|c|c|c|c|c|c|}
\hline \multirow[b]{2}{*}{ Phages } & \multicolumn{4}{|c|}{ Indicator and parental strains } & \multicolumn{6}{|c|}{ Recombinants } \\
\hline & 66 & A6I 7, SI 8 & $\mathrm{~K} 806$ & KI 55 & RcgI & $\mathrm{Rcg}_{3}$ & Rcg5 & $\mathrm{Rcg} 7$ & $\mathrm{Rcg} 2$ & $\operatorname{Rcg}_{I}$ \\
\hline$\phi 448$ & 48 & $5 \mathrm{I}$ & $<0.00 \mathrm{I}$ & $<0.001$ & 55 & 58 & 53 & 48 & $<0.001$ & $<0.001$ \\
\hline $\mathrm{VP}_{5}$ & 54 & 49 & $<0.001$ & $<0.00 \mathrm{I}$ & 52 & 54 & 60 & 52 & 58 & 50 \\
\hline Pg8I & $<0.001$ & $<0.001$ & 58 & 50 & $<0.001$ & $<0.001$ & $<0.001$ & $<0.001$ & $5 \mathrm{I}$ & 49 \\
\hline Pgioo & $<0.001$ & $<0.001$ & 52 & $5 \mathrm{I}$ & $<0.001$ & $<0.001$ & $<0.001$ & $<0.001$ & 50 & 52 \\
\hline Pg56 & $<0.001$ & $<0.001$ & 62 & 60 & $<0.001$ & $<0.001$ & $<0.001$ & 59 & 58 & 60 \\
\hline
\end{tabular}

Table 8. Efficiencies of actinophage plating on actinomycete strains

\begin{tabular}{|c|c|c|c|c|c|c|c|c|c|}
\hline \multirow[b]{3}{*}{ Phages } & & & & & \multicolumn{5}{|c|}{ Recombinants from crosses } \\
\hline & \multicolumn{4}{|c|}{ Indicator and parental strains } & A6I $7 \times \mathrm{K} 806$ & \multicolumn{3}{|c|}{$\mathrm{KI} 55 \times \mathrm{RcgI}$} & \multirow{2}{*}{$\begin{array}{c}\text { SI } 8 \times \text { K } 806 \\
\text { RcgII }\end{array}$} \\
\hline & 66 & A6I 1 , SI 8 & K806 & KI 55 & $\operatorname{Rcg} I, \operatorname{Rcg}_{3}$ & $\operatorname{Rcg} 5$ & $\mathrm{Rcg} 7$ & $\operatorname{Rcg} 2$ & \\
\hline$\phi 448$ & $I \cdot 0$ & $I \times 10^{-1}$ & $\ldots *$ & - & $1 \times 10^{-1}$ & $1 \times 10^{-1}$ & $<\mathrm{I} \times 10^{-1}$ & - & - \\
\hline $\mathrm{VP}_{5}$ & $I \cdot O$ & $I \cdot O$ & $\ldots$ & - & $\mathrm{I} \cdot \mathrm{O}$ & $1 \cdot 0$ & 1.0 & $<\mathrm{I} \times \mathrm{IO}^{-7}$ & $<\mathrm{I} \times 1 \mathrm{IO}^{-7}$ \\
\hline Pg8I & - & - & $I \cdot O$ & $<\mathrm{I} \times \mathrm{IO}^{-9}$ & - & - & - & $1 \times 10^{-4}$ & $3 \times 10^{-5}$ \\
\hline Pgroo & 一 & - & $I \cdot O$ & $1 \cdot 0$ & 一 & - & - & $<\mathrm{I} \times \mathrm{IO}^{-8}$ & $<\mathrm{I} \times 10^{-8}$ \\
\hline Pg56 & 一 & - & $I \cdot 0$ & $1 \times 10^{-1}$ & - & - & $<5 \times 10^{-7}$ & $\mathrm{I} \times 10^{-1}$ & I. 0 \\
\hline
\end{tabular}


Table 9. Efficiencies of plating of $\mathrm{Pg} 8 \mathrm{I}$ on strains $\mathrm{K} 806, \mathrm{Rcg} 2$ and $\mathrm{Rcg} \mathrm{I}$

\begin{tabular}{lccc} 
& \multicolumn{3}{c}{$\begin{array}{c}\text { Relative e.o.p. of phage Pg8I } \\
\text { lysates prepared from strains: }\end{array}$} \\
Host strain & $\mathrm{K} 806_{\mathrm{Rcg} 2}$ & $\mathrm{R} \operatorname{cg}$ I I \\
K806 & $\mathrm{I}$ & $\mathrm{I} \times 10^{-7}$ & $3 \times 10^{-7}$ \\
Rcg2 & $\mathrm{I} \times 10^{-4}$ & $\mathrm{I}$ & $\mathrm{I}$ \\
RcgI I & $3 \times 10^{-5}$ & $\mathrm{I}$ & $\mathrm{I}$
\end{tabular}

and RcgI I gave plaques as large as on $S$. griseus $\mathrm{K} 806$ though with lower efficiencies of plating (e.o.p), $\mathrm{I} \times \mathrm{IO}^{-4}$ and $3 \times 10^{-5}$. Phages from large plaques when growing in Rcg2 or RcgI I gave a high e.o.p. on these strains and were restricted in S. griseus K806 (Table 9).

\section{DISCUSSION}

Under conditions that reduced the effect of antibiotic inhibition (in the presence of streptomycin, or after transfer of young mixed culture to a medium containing streptomycin), colonies with the properties of heteroclones arose on selective plates from crosses between $S$. griseus str-s and $S$. coelicolor UF $\left(\mathrm{SCP}_{I^{-}}{ }^{-}\right)$str-r strains: they were unable to grow on the same medium and could generate heterogeneous progeny. Despite the fact that in the progeny of these colonies most variants had the genotype of $S$. coelicolor, some variants which differed from both parental strains in their genotypes were also detected. However, only a limited number of recombinant classes were revealed in the progeny of such colonies unlike the situation when heteroclones formed in crosses between $S$. coelicolor strains were analysed. Infrequent crossing-over between the chromosomes of $S$. coelicolor and $S$. griseus may be explained by imperfect homology, or the possibility that heteroclones and recombinants generated in crosses between $\mathrm{A3}(2)$ derivatives are structurally different from those formed in the cross between $S$. coelicolor and $S$. griseus. The latter may possess a fragment of the $S$. griseus chromosome that is not integrated into the chromosome of $S$. coelicolor. Such extrachromosomal elements may be lost or preserved in heteroclone progeny. The cells containing such fragments phenotypically may resemble haploid recombinants.

Characteristics of representatives of the recombinant classes were studied. Some recombinants failed to produce the antibiotic that inhibits SCPI-carrying and $\mathrm{SCPI}^{-}$ strains of $S$. coelicolor. Rcg r resembled $S$. coelicolor $\mathrm{SCPI}^{-}$strains in its inability to arrest SCPI-carrying strains and in its sensitivity to the antibiotic produced by SCPI-carrying strains. In crosses with $S$. coelicolor, the SCPI-carrying NF strain RcgI behaved like a recipient. Only recombinant progeny were produced in these crosses. Zygotes from such crosses are polarized and asymmetric since the chromosomal fragment is derived from the $S$. coelicolor NF strain. In crosses between $S$. griseus strain KI55 and RcgI, colonies having properties of heteroclones arose at a high frequency. Rcg3 phenotypically resembled a SCPI-carrying strain in its ability to inhibit only $\mathrm{SCPI}_{\mathbf{I}}-$ strains and in its resistance to the antibiotic produced by SCPI-carrying $S$. coelicolor strains. In crosses between $\mathrm{Rcg}_{3}$ and a $S$. coelicolor UF strain, recombinants appeared at high frequency. However, unlike $S$. coelicolor $\mathrm{NF} \times$ UF crosses, variants with parental genotypes were detected in the progeny and a distinct ratio of recombinant classes was observed. The reason for this phenomenon is not obvious. The differences could be related to an anomaly imposed by the absence of crossovers between chromosomes of $\mathrm{R}_{\mathrm{cg}} 3$ and strain $\mathrm{A}_{585}$ in a region of $\mathrm{Rcg}_{3}$ containing 
a fragment of the $S$. griseus chromosome with the $u r a A I^{+}$marker. For example, recombinants formed by crossovers in regions $a, b$ and $c$ (Fig. 3) and rarely detected in the progeny from crosses between A3(2) strains, may be revealed more often in the progeny from the cross $R \mathrm{Rg}_{3} \times \mathrm{A}_{585}$. However, other explanations must also be considered.

Donor properties of $S$. griseus are indicated by the isolation from crosses between $S$. griseus and a $S$. coelicolor recipient strain of the recombinant $\operatorname{Rcg} 3$ which had donor strain properties, and by the effective transfer of $S$. griseus chromosomal genes into Rcg I. Also, Rcg3 was able to arrest the growth of $\mathrm{SCPI}^{-}$strains of $S$. coelicolor. This donor ability may be related to the presence in $\mathrm{Rcg}_{3}$ and $S$. griseus of a plasmid resembling SCPI.

Our results also demonstrate the haploid nature of the isolated recombinants. All of them, RcgI, Rcg3, RcgI I derived from crosses between $S$. griseus and $S$. coelicolor and Rcg2, Rcg5 and Rcg7 from crosses between $S$. griseus and RcgI, were stable and did not segregate clones of the recipient genotype. In addition, the functioning of the recessive allele of the donor for histidine requirement is expressed in Rcg5, and the other donor character, i.e. the absence of the ability to adsorb actinophage $\phi 448$ (that may be considered as a recessive character provided the recipient strain is able to adsorb this phage) is expressed in Rcg2 and RcgII. Further studies are needed to determine whether stable integration of a fragment of the S. griseus chromosome into the chromosome of $S$. coelicolor takes place. RcgI, Rcg3 and Rcg5 were, like $S$. coelicolor, hosts for a number of phages, whereas Rcg2, Rcg7 and RcgI I differed from both parents in this respect. The behaviour of RcgI, Rcg3 and Rcg5 suggests that they lack genes controlling phages Pg8r, PgIoo and $\mathrm{Pg}_{5} 6$ receptor synthesis and that genes essential for $\phi 448$ and VP5 adsorption and growth are located in the fragment of these recombinants which was derived from the $S$. coelicolor chromosome. Recombinant Rcg7, unlike $S$. coelicolor, acquired the gene for adsorption of actinophage $\mathrm{Pg}_{56}$. Since the growth of phage $\mathrm{Pg}_{56}$ is limited in $\mathrm{Rcg} 7$, we take this to mean that it is connected with the absence in the recombinants of those genes of the $S$. griseus chromosome involved in the control of intracellular phage growth. Alternatively, it is possible that the gene responsible for $\mathrm{Pg}_{5} 6$ growth limitation is located in the particular fragment of the $S$. coelicolor chromosome contributed to Rcg7. The genes for $\phi 448$ and $\mathrm{VP}_{5}$ adsorption and those responsible for phage growth may be located in the same fragment.

Rcg2 and RcgI I contain genes responsible for adsorption of phages Pg8I, PgI00, $\operatorname{Pg}_{5} 6$ and VP5. However, only phage Pg56 was capable of growing in Rcg2 and RcgII. When plated on Rcg2 and RcgII, phage Pg8I gave rise to modified phage, the latter producing high yield in these hosts. The phage was also restricted in $S$. griseus. Thus, we assume that $S$. coelicolor has a restriction and modification system. The data also imply that two different systems of restriction and modification of phage DNA exist in $S$. coelicolor and S. griseus.

The growth limitation of phages $\mathrm{Pg}_{100}$ and $\mathrm{VP}_{5}$ in Rcg2 and RcgII strains may be the result of the absence in hybrids of genes essential for phage intracellular growth, or the presence of host genes acting by a mechanism distinct from that for restriction and modification. The data presented show the possibility of obtaining hybrids with desired characteristics, for example, strains that produce grisin and are resistant to phages which lyse industrial grisin-producers. In the course of these studies we obtained recombinants (Rcg2 and RcgII) which were able to produce grisin under conditions of liquid growth in amounts similar to those of the parental strains, $S$. griseus KI55 and K806. They were also resistant to phage $\phi 448$ and restricted phages VP5, Pg8I and PgIoo. Thus they did not support growth of two phages acting on S. coelicolor, and two acting on $S$. griseus. 


\section{REFERENCES}

Alačević, M., Strašek-Vešligaj, M. \& Sermonti, G. (1973). The circular linkage map of Streptomyces rimosus. Journal of General Microbiology 77, 173-185.

AlikHANIAN, S. I. (I969). Induced mutagenesis as related to variation in quantitative features (antibiotic production). In Proceedings of the International Symposium on Genetics and Breeding of Streptomyces, pp. 69-87. Edited by G. Sermonti and M. Alačević. Zagreb: Yugoslav Academy of Sciences and Arts.

Alikhanian, S. I., LomovskayA, N. D. \& Danilenko, V. N. (1976). Suppressor-sensitive mutations of Streptomyces coelicolor $\mathrm{A}_{3}(2)$ and actinophage $\phi \mathrm{C}_{3} \mathrm{I}$. In Proceedings of the Second International Symposium on the Genetics of Industrial Microorganisms, pp. 595-606. Edited by K. D. Macdonald. London, New York, San Francisco: Academic Press.

Baron, L. S., Penido, E., Ryman, I. R. \& Falkow, S. (1970). Behaviour of coliphage lambda in hybrids between $E$. coli and Salmonella. Journal of Bacteriology 102, $22 \mathrm{I}-223$.

BaumanN, R. \& Kocher, H. P. (1976). Genetics of Streptomyces glaucescens and regulation of melanin production. In Proceedings of the Second International Symposium on the Genetics of Industrial Microorganisms, pp. 535-55I. Edited by K. D. Macdonald. London, New York, San Francisco: Academic Press.

Brenner, D. J. \& Falkow, S. (I97I). Molecular relationships among members of the Enterobacteriaceae. Advances in Genetics 16, 81-1 8 .

Cannon, F. C., Dixon, R. A., Postgate, J. R. \& Primrose, S. B. (1974). Chromosomal integration of Klebsiella nitrogen fixation genes in E. coli. Journal of General Microbiology 20, 227-239.

COATs, I. H. \& Roeser, J. (197I). Genetic recombination in Streptomyces bikiniensis var. zorbonensis. Journal of Bacteriology 105, 880-885.

Colson, A. M. \& Colson, C. (1972). Expression of the Escherichia coli $\mathrm{K}, \mathrm{B}$ and phage PI DNA host specificities in Salmonella typhimurium. Journal of General Microbiology 70, $123-128$.

Delić, V., Hopwood, D. A. \& Friend, E. J. (1970). Mutagenesis by $N$-methyl- $N^{\prime}$-nitro- $N$-nitrosoguanidine (NTG) in Streptomyces coelicolor. Mutation Research 9, I67-182.

DemEREC, M. (1965). Homology and divergence in genetic material of Salmonella typhimurium and Escherichia coli. In Evolving Genes and Proteins, pp. 505-510. Edited by V. Bryson and H. J. Vogel. New York, London: Academic Press.

FRIEDMAN, D. I. \& BARON, L. S. (1974). Genetic characterization of a bacterial locus involved in the activity of the $\mathrm{N}$ function of phage $\lambda$. Virology $58, \mathrm{I} 4 \mathrm{I}-148$.

FRIEND, E. J. \& Hopwood, D. A. (I97I). The linkage map of Streptomyces rimosus. Journal of General Microbiology 68, I87-197.

Gemski, J. R., AleXeichik, J. A. \& Baron, L. S. (1972). Behaviour of coliphage lambda in Shigella flexneri 2a. Journal of Virology 10, 668-674.

HAYES, W. (1952). Recombination in Bact. coli KI2: unidirectional transfer of genetic material. Nature, London 169, I I 8-1 19.

Hopwood, D. A. (1967). Genetic analysis and genome structure in Streptomyces coelicolor. Bacteriological Reviews 3r, 373-403.

Hopwood, D. A. (1973). Developments in actinomycete genetics. In Proceedings of the International Symposium on the Genetics of Industrial Microorganisms, pp. 21-46. Prague: Academia.

Hopwood, D. A. \& Wright, H. M. (I973). Transfer of plasmid between Streptomyces species. Journal of General Microbiology 77, I87-I95.

Hopwood, D. A., Harold, R. J., Vivian, A. \& Ferguson, H. M. (I969). A new kind of fertility variant in Streptomyces coelicolor. Genetics 62, 461-477.

Hopwood, D. A., Chater, K. F., Dowding, J. E. \& Vivian, A. (1973). Advances in Streptomyces coelicolor genetics. Bacteriological Reviews 37, 37I-405.

KorZYBSKI, T., KowsZYK-Gindifer, Z. \& KuRYŁowicz, W. (I969). In Antybiotyki, vol. I, pp. 273-274. Warszawa: Panstwowy Zaklad wydawnichw Lekarskich.

Krasilnikov, N. A. (1970). Actinomycetales, pp. 136, 229, 300. Moscow: Nauka.

Lomovskaya, N. D., Emeljanova, L. K. \& Alikhanian, S. I. (I97I). The genetic location of prophage on the chromosome of Streptomyces coelicolor. Genetics 68, 34I-347.

Lomovskaya, N. D., Mkrtumian, N. M., Gostimskaya, N. L. \& Danilentro, V. N. (i972). Characterization of temperate actinophage $\phi \mathrm{C}_{3} \mathrm{I}$ isolated from Streptomyces coelicolor $\mathrm{A} 3(2)$. Journal of Virology 9, $258-262$.

MatSElyukH, B. P. (1976). Structure and function of the Actinomyces olivaceus genome. In Proceedings of the Second International Symposium on the Genetics of Industrial Microorganisms, pp. 553-563. Edited by K. D. Macdonald. London, New York, San Francisco: Academic Press.

SANDERSON, K. E. (1971). Genetic homology in the Enterobacteriaceae. Advances in Genetics I6, 35.

VIVIAN, A. (197I). Genetic control of fertility in Streptomyces coelicolor A3(2). Plasmid involvement in the interconversion of UF and IF strains. Journal of General Microbiology 69, 353-364.

Vivian, A. \& Hopwood, D. A. (1970). Genetic control of fertility in Streptomyces coelicolor A3(2): the IF fertility type. Journal of General Microbiology 64, IOI-I I7.

Zvenigorodsky, V.I., Voeikova, T. A., Yustratova, L. S., Smirnova, E. I. \& Lomovskaya, N. D. (1975). Characteristics of actinophages of Actinomyces griseus and selection of phage-stable mutants of grisinproducing organism. Antibiotics (in Russian) 20, 409-4I 5. 